\title{
Patrolling the Scottish Border - plant migration history
}

\author{
Michael E. Braithwaite \\ Hawick, Scotland
}

Corresponding author: mebraithwaite@btinternet.com

This pdf constitutes the Version of Record published on $7^{\text {th }}$ December 2020

\begin{abstract}
There have been successive waves of plant migration north across the Scottish

Border since the end of the Ice Age. For those species that never penetrated far into Scotland and which lack specialised means of long-distance dispersal, the distinctive distribution patterns shown by BSBI's tetrad mapping provide evidence of the likely dates and dispersal mechanisms of the migrations, separating out migration relating to man's activities. Twelve distribution maps have been prepared for native or archaeophyte species that illustrate contrasting histories. Conclusions are drawn as to whether or not species which lack specialised means of long-distance dispersal are able to migrate north over fragmented natural habitats in response to climate change.
\end{abstract}

\section{Key words}

Tetrad mapping; dispersal mechanisms; climate change; native species.

\section{Introduction}

My botanising in the Scottish Borders now spans fifty years and I have had the privilege of witnessing many changes in the flora at first hand. The most dramatic change was the colonisation of road verges by halophytes such as Spergularia marina in the 1990s. It opened my eyes to just how rapid plant migration can be if a new habitat, such as roads salted in winter, is opened up. It has now occurred to me to investigate whether the distinctive patterns of the tetrad distributions, now available online at the BSBI's Distribution Database (DDb), throw light on the migrations of other species that have crossed the Scottish Border over the centuries.

I have searched the New Atlas (Preston et al, 2002) for native and archaeophyte species whose distribution only just reaches north into Scotland and have selected contrasting species, all of which I am familiar with, for detailed review. I have searched in vain for native species that appear to have migrated north to Scotland more recently than the Neolithic period without assistance from man's activities, unless they have specialised means of long-distance dispersal. Groups of species with specialised means of dispersal are ferns and orchids, dispersed by minute propagules carried in the wind, many of the Onagraceae, whose seeds have silky hairs that lift the seed efficiently in the wind, as do, but less efficiently, many of the Asteraceae. Many aquatic species are effectively dispersed by waterfowl, many maritime species have fruits that survive dispersal by the sea and many arable weeds have always depended on man's activities. Trees and shrubs that have juicy fruits dispersed by birds are also excluded, as they are either very widespread or 
have a long history of deliberate plantings that has obscured their natural distribution. Montane, moorland and many wetland species colonised across Scotland soon after the Ice Age and have thus had no cause to spread north since then. So the species left for review are all lowland species and include many grassland species, a few woodland species and a few wetland species. I have included some of the Asteraceae, where the wind-dispersal of their seeds seems only to be effective over short distances.

\section{The physical setting}

Following studies of the pollen record preserved in peat deposits, it is generally agreed that extensive grassland did not develop in Britain until the forest clearances of the Neolithic period, when man burned forests to obtain grazing for domesticated animals and land to cultivate. In Scotland, these clearances started around 3,000 BC and were made by a mainly pastoral society. However wild cattle, aurochs, were present earlier and presumably opened a network of forest glades and some species are likely to have colonised earlier along coasts, so it is unclear when the more southern grassland species spread to Scotland. Furthermore, some of what we tend to regard as grassland species are more accurately described as woodland-edge species, and would have been able to colonise a predominantly wooded landscape.

The Scottish Border is mainly upland, following the line of the Cheviot Hills, with relatively narrow lowland corridors following the coast near Berwick upon Tweed on the east and Carlisle on the west. The opportunity for a species to pass along these corridors depends on the availability of suitable habitat. Once across the Border a colonising species has been faced with a change in the underlying geology from predominantly sedimentary rocks of the Carboniferous, both sandstone and limestone, to predominantly metamorphic rocks of the Silurian. Most of the Southern Uplands is acid and it presents a formidable barrier to migration north. However much of the Silurian in the Tweed Valley is less acid, with folded strata of calciferous sandstone at unpredictable intervals. There is also a belt of the Old Red Sandstone, but, rather surprisingly, its flora is broadly similar to that on the less-acid parts of the Silurian.

The habitats also differ from those to the south. In the east, the Scottish Borders had a great deal of wetland and wet woodland on the low ground, with drier woodland on the higher ground, later reduced by forest clearance. Opportunities for the more specialised grassland species were confined to the coastal braes, some riverside banks and some of the more calcareous slopes of the rocky knowes (hillocks) which are often intrusive igneous rocks. It may be supposed that these grassland habitats were available to varying degrees over the ages as the woodland cover waxed and waned, while the more specialist grassland species may have used rocky slopes as refugia when woodland increased, as woodland cover would never have been complete there.

\section{Interpreted maps for the selected species}

\section{The maps}

Each of the maps shows the tetrad $(2 \mathrm{~km})$ distributions of two species, using data from the DDb unclassified by date-class (but mainly after 1950). For England the great majority of the tetrads have been surveyed at some date, while for Scotland coverage is much less complete and varies across the country. For upland areas with 
uniform vegetation only about one in eight tetrads have been surveyed, for lowland areas the coverage is much better, especially for the scarcer species which may have been exhaustively surveyed in their distinctive habitats.

The selected species is mapped on top in blue, with a comparable species below in green. The comparable species may be a second selected species (in the case of Scleranthus annuus), or a familiar species that is rather more widespread.

\section{Interpreting the maps - 'coherent' distributions}

For species which lack specialised means of long-distance dispersal the initial distribution is 'coherent' in the sense that, at tetrad scale, its map consists of contiguous 'dots' snaking across the landscape as its migration follows suitable habitats, particularly those defined by the underlying geology. An initially contiguous distribution may subsequently become fragmented for a variety of reasons, chiefly related to man's activities, but in many cases can still be picked out with confidence by eye. Distribution maps frequently have a coherent distribution over part of the species' range and scattered 'dots' over a wider range. The scattered dots are often readily attributed to man's activities. Some are deliberate introductions, and may have been recorded as such, while many others are unwittingly introduced in crop seeds, construction materials or by their seeds adhering to vehicles. The introductions may naturalise widely, narrowly or not at all.

Tetrad maps of a declining species can be thought of as looking back in time. As even a single plant in an area of 400 hectares counts as a 'dot', it is as if one is looking back to a time when the species was more plentiful. For this reason tetrad maps continue to be 'coherent' long after a species starts to decline.

\section{The Boreal Period}

Dianthus deltoides and Scleranthus annuus are two relatively scarce grassland species of sandy grassland and rock outcrops. The map (Fig. 1) shows remarkably fragmented northern distributions for both species. The fragmentation is extreme for $D$. deltoides, while the distribution of $S$. annuus is more coherent and gives an indication of likely migration routes for both species from the south, making much use of sandy coastal grassland.

One possibility is that both species colonised during the Boreal period around $7,000 \mathrm{BC}$, when the climate was dry with cold winters and short warm summers, but suffered many local extinctions in the Atlantic period around 5,000 BC when the wetter climate would have allowed denser grass swards to develop.

Another possibility is that colonisation occurred during a period of mainly pastoral farming in the Neolithic and soon began to lose ground when the easily cultivated light soils were first ploughed, a decline that has continued to the present day. Scleranthus annuus survived longer than $D$. deltoides because it is an annual that could persist as an arable weed. In Scotland today, both species are largely confined to uncultivated rock outcrops. 


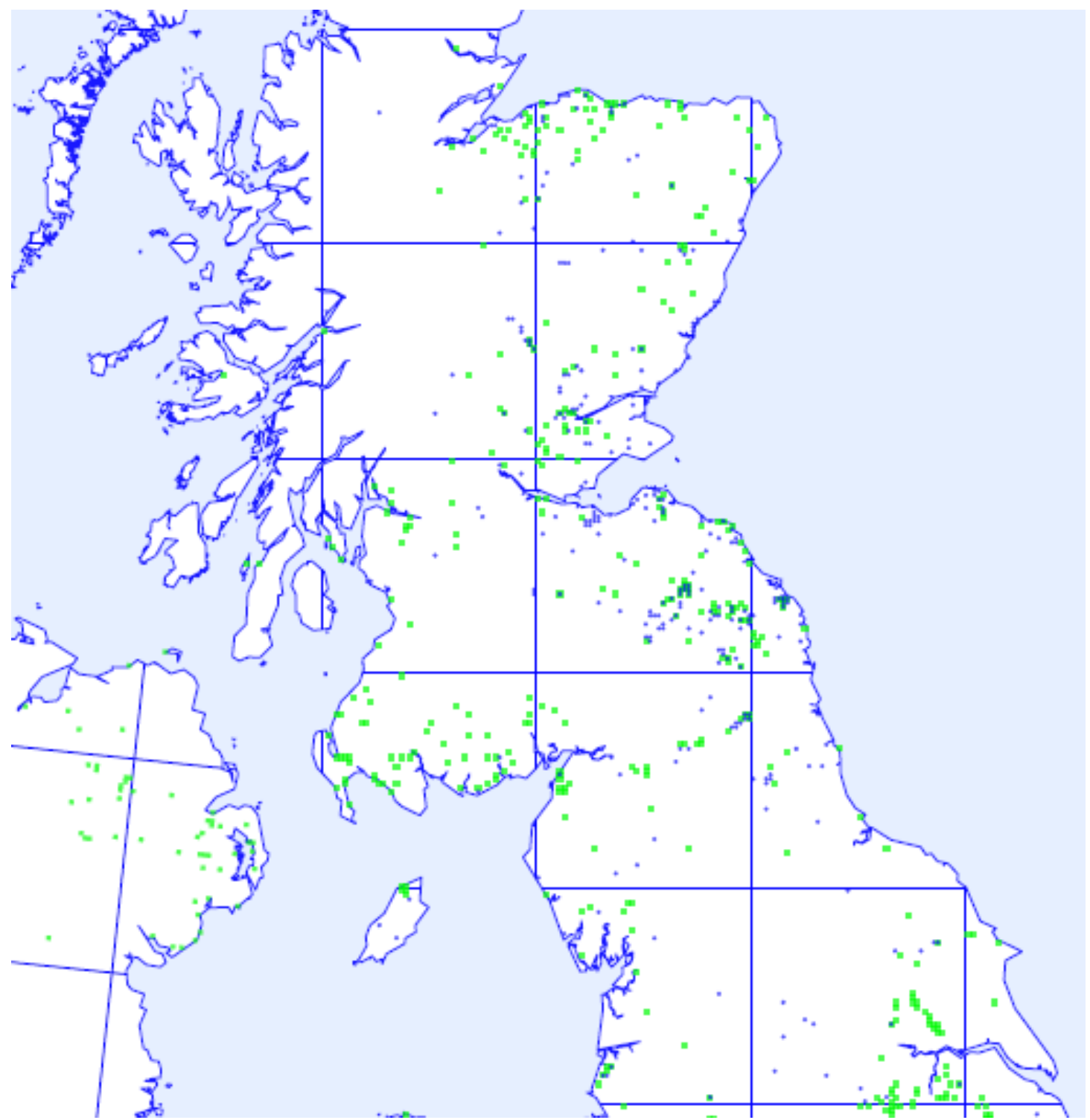

Figure 1. Dianthus deltoides (blue) over Scleranthus annuus (green)

The Neolithic Period

The map of Scabiosa columbaria over Leontodon hispidus (Fig. 2) shows coherent distribution patterns for two grassland species that reached Scotland but did not penetrate further than the Central Belt. Scabiosa columbaria is a strict calcicole that avoids skeletal soils and whose fruit appears adapted to adhering to animals, while L. hispidus is a species of neutral and calcareous soils that is distributed relatively inefficiently by wind. It is suggested that both species colonised across the Border into Scotland during the Neolithic period. 


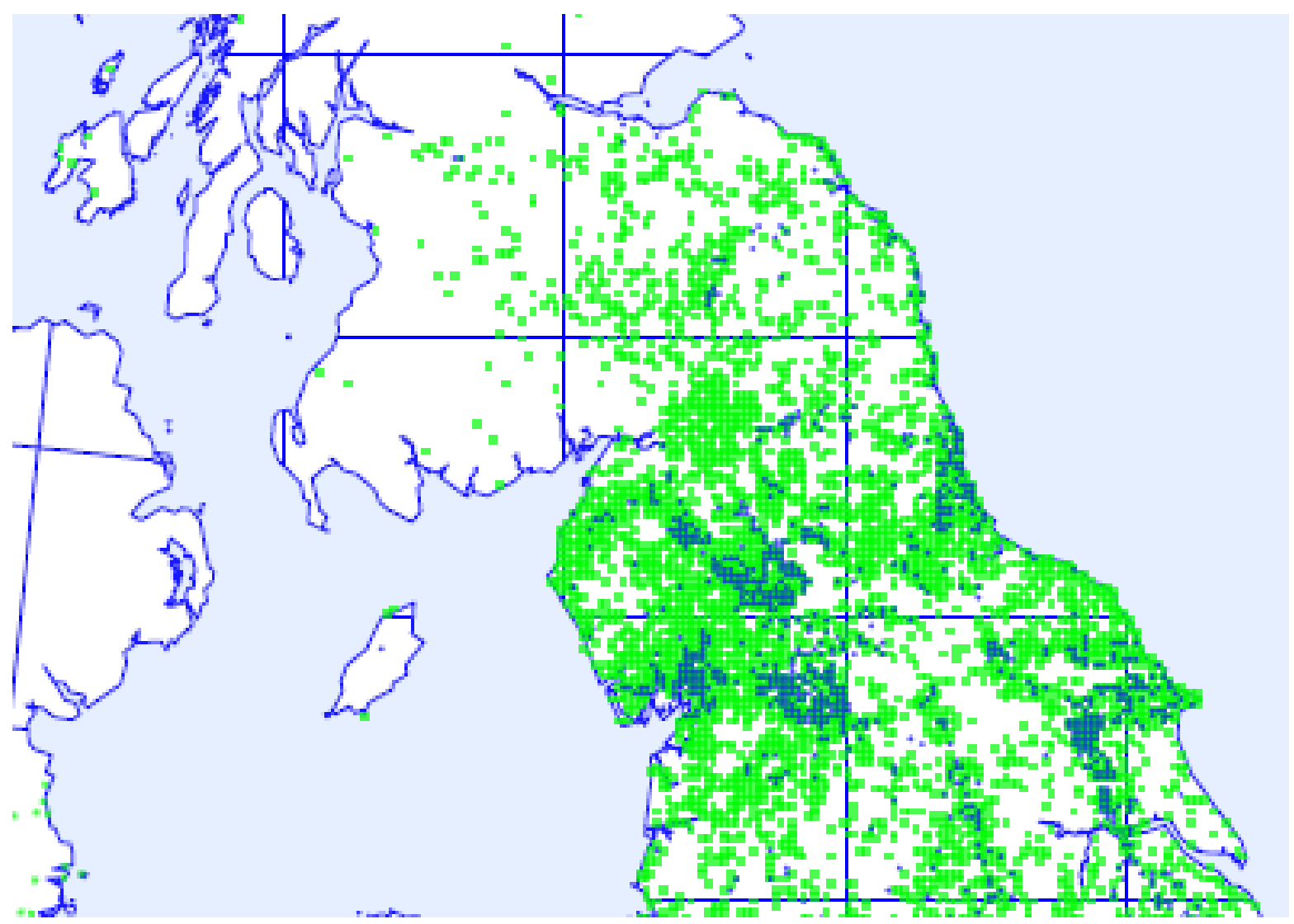

Figure 2. Scabiosa columbaria (blue) over Leontodon hispidus (green)

\section{The Roman Period}

The map of Spergularia rubra over Arenaria serpyllifolia (Fig. 3) displays two species that have colonised very widely in response to man's activities over a long period of time, conjecturally since the road construction programme of the Roman Period. The distributions of both species have been changing in recent years, but there are likely to have been many such changes over the centuries in response to changes in road building practice and, more recently, to railway construction.

Spergularia rubra is a sand specialist that seems to be unable to coexist with grassland species of thin soils such as Geranium pusillum and Sherardia arvensis. Spergularia rubra is seemingly native in a few areas in the south, mainly near the coast, but elsewhere it is a colonist and may not be native anywhere in Scotland. It multiplies in sand and gravel pits and can then be spread to roads during construction work or by vehicles to brownfield sites, forestry tracks and the like.

As a native, $A$. serpyllifolia is a specialist of scree and grit on rocky slopes, becoming relatively scarce in Scotland, but it colonises road-stone quarries and railway ballast and is then dispersed widely. 


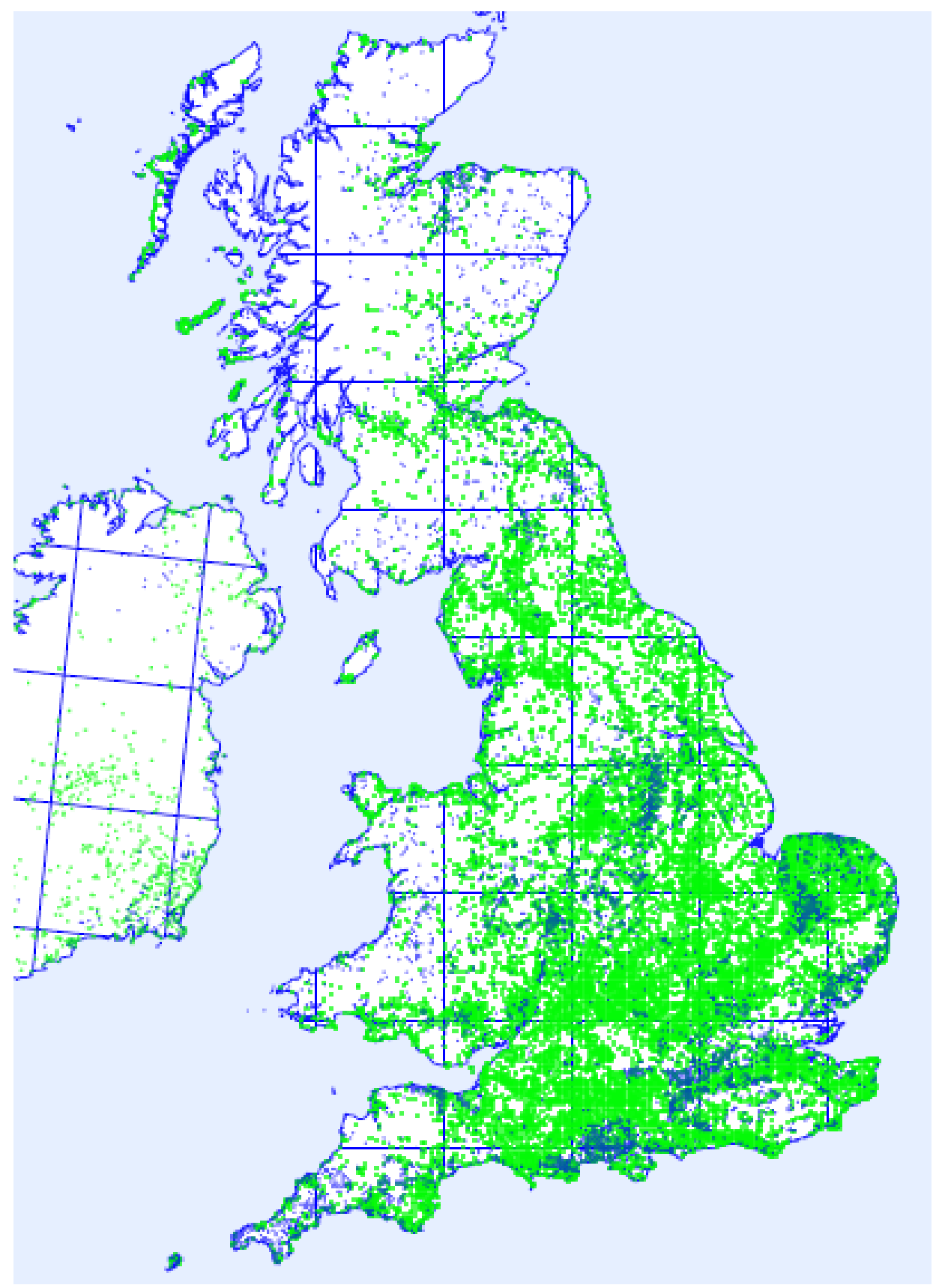

Figure 3. Spergularia rubra (blue) over Arenaria serpyllifolia (green)

The 'Dark Ages'

Myrrhis odorata (Fig. 4) is an unequivocal archaeophyte, formerly used as a flavouring, which is often found by old farmsteads, where its introduction may date as far back as the Anglian invasion around $600 \mathrm{AD}$, on the basis of place-name evidence (Braithwaite, 2016). It has naturalised quite widely in Scotland, especially along river banks where its seeds have been thrown up by floods. It is mapped against a background of Geranium sy/vaticum which is more of a hill plant, though with a similar overall distribution. The distribution of M. odorata demonstrates how a coherent distribution can develop from multiple introductions. 


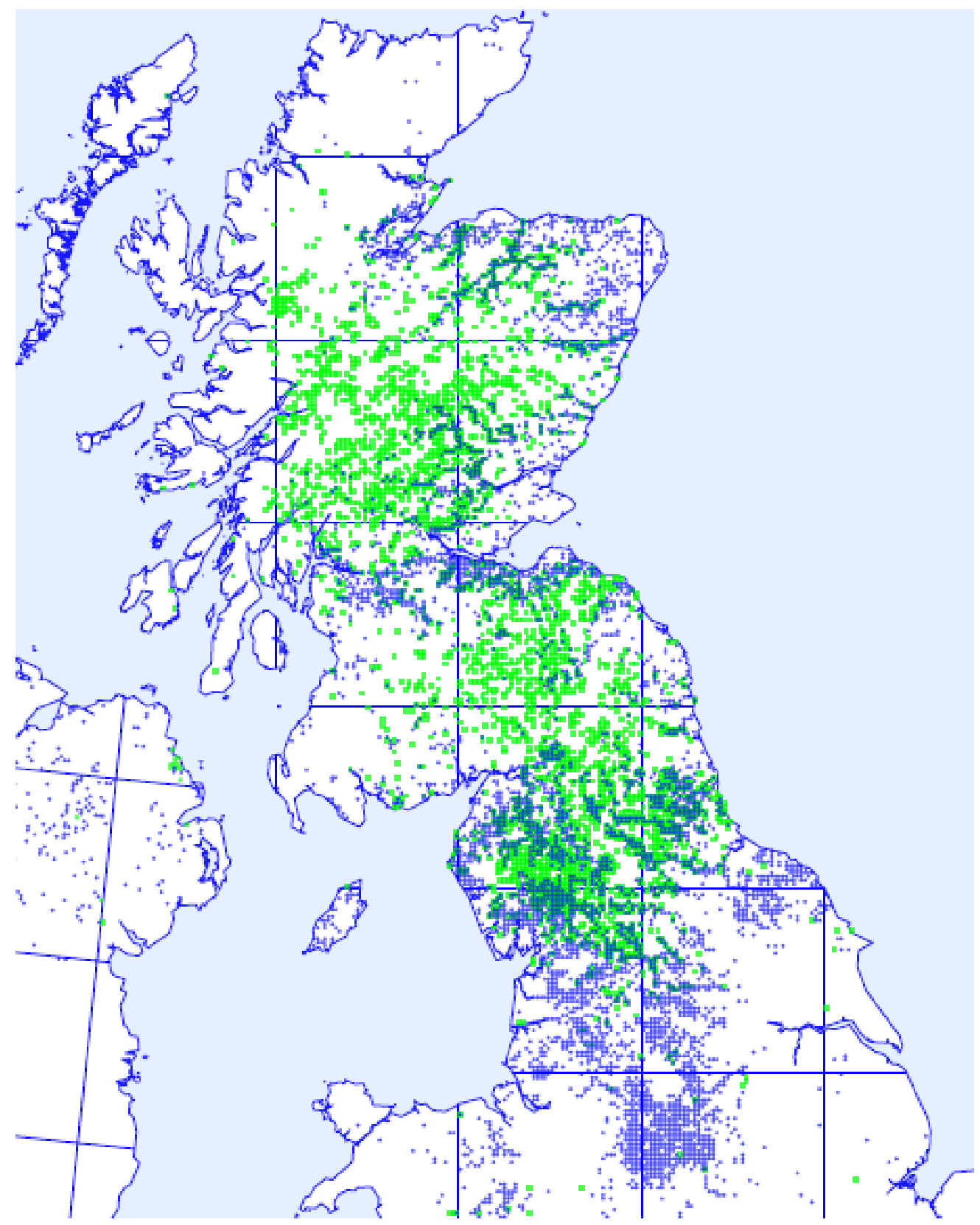

Figure 4. Myrrhis odorata (blue) over Geranium sylvaticum (green)

The 'Middle Ages'

The map of Betonica officinalis over Leontodon hispidus (Fig. 5) is perplexing. In much of northern England, but not in the south, B. officinalis is a weak calcicole of relatively fertile soils that is as much a woodland-edge plant as a grassland plant. It is very widespread, though rather local, across much of England, including Cumbria and South Northumberland, but with only the thinnest scatter of sites in Scotland. It is very difficult to explain any part of the Scottish distribution as natural, as circumstances before the days of botanical recording that could have caused a severe decline in Scotland of a formerly more widespread species would have equally affected the populations in the north of England. Betonica officinalis is a recent introduction at many of its Scottish sites, usually introduced with conservation sowings that include a flourishing colony on a rock cutting that is part of a 
realignment on the A1 trunk road in Berwickshire. However some of the Scottish Borders sites and even a site in Perthshire have usually been accepted as native. This may be a fallacy. Betonica officinalis has a long history as a medicinal herb and might have been introduced as such and then have naturalised narrowly. That it has not naturalised more widely is puzzling. It may be an indication that $B$. officinalis was not introduced in prehistoric times but in the Middle Ages, and then only to already-fragmented habitats near farmsteads. The climate may also have played a part, $B$. officinalis is a late-flowering species and seed-set might be affected by early frosts.

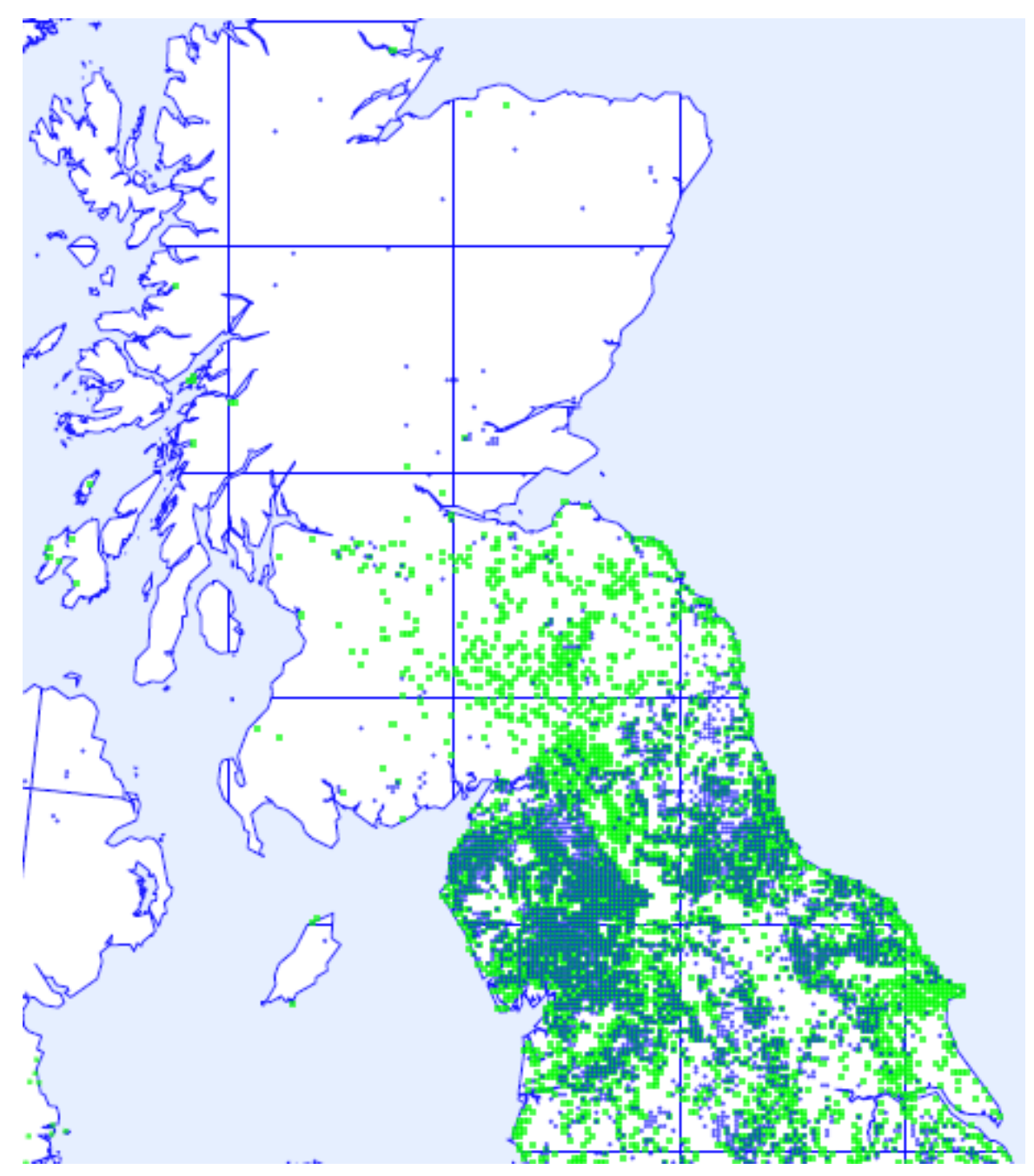

Figure 5. Betonica officinalis (blue) over Leontodon hispidus (green)

\section{The Eighteenth Century}

Myosotis sy/vatica (Fig. 6) was unquestionably introduced as a garden plant from quite an early date, but more particularly from the eighteenth century. However it is debateable how far north its native distribution reached. It might or might not be a Scottish native. It has certainly been increasing across Scotland, suggesting an introduction. While it has naturalised widely down river valleys, forming a locallycoherent distribution, it remains scarce or absent in many areas. It is mapped over Mercurialis perennis. 


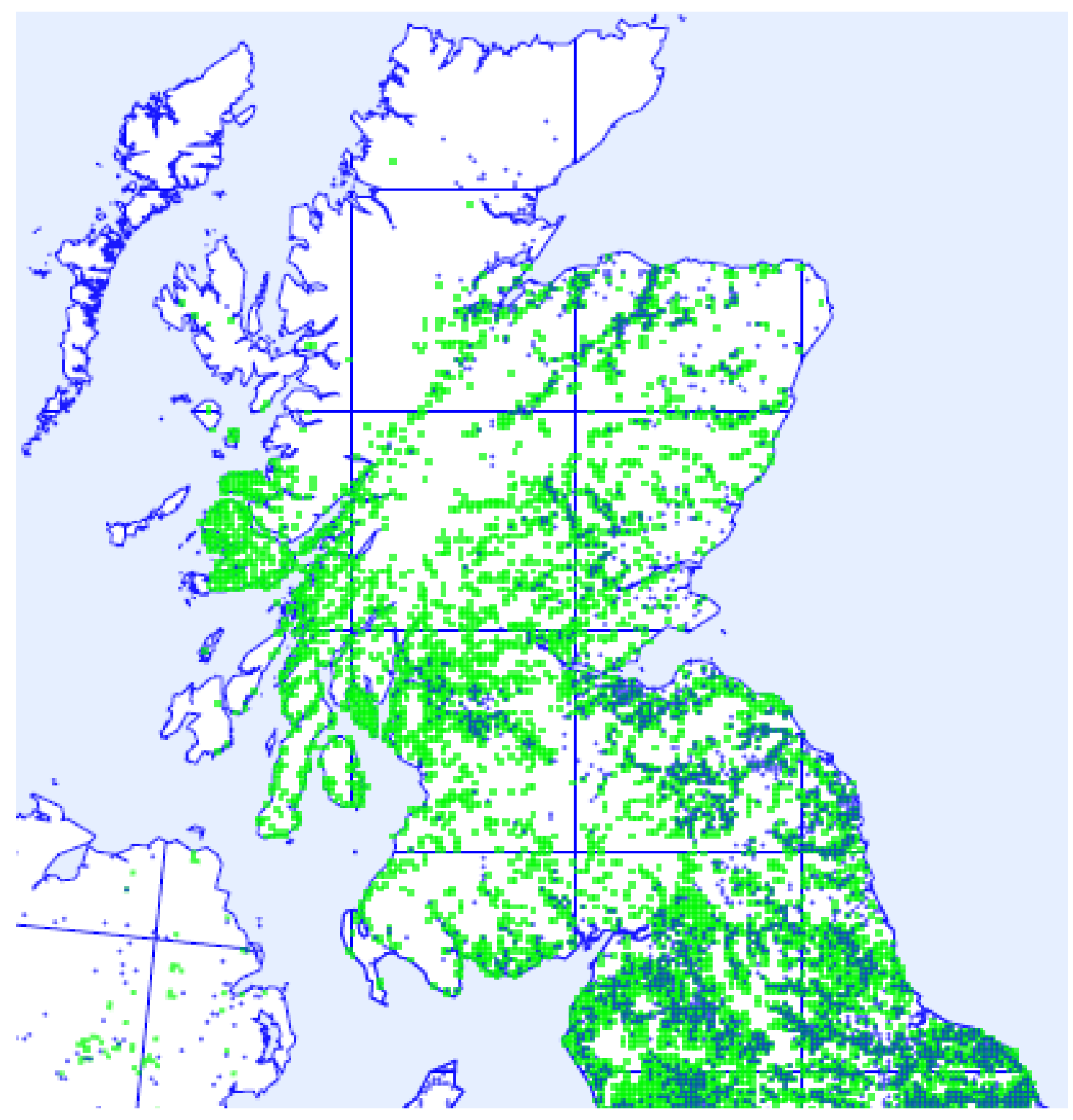

Figure 6. Myosotis sylvatica (blue) over Mercurialis perennis (green)

The Nineteenth Century

Arum maculatum (Fig. 7) has been cultivated as a curiosity since early times, but it was more widely introduced in the nineteenth century and has naturalised freely in the policy woodlands of the great houses and thence to other woodland. Its fruits are dispersed by birds, but long-distance dispersal is not suspected. Its native range is debateable, but my field experience in the Scottish Borders strongly suggests that it is an introduction there and thus, presumably, in the rest of Scotland. It is mapped over Mercurialis perennis. 


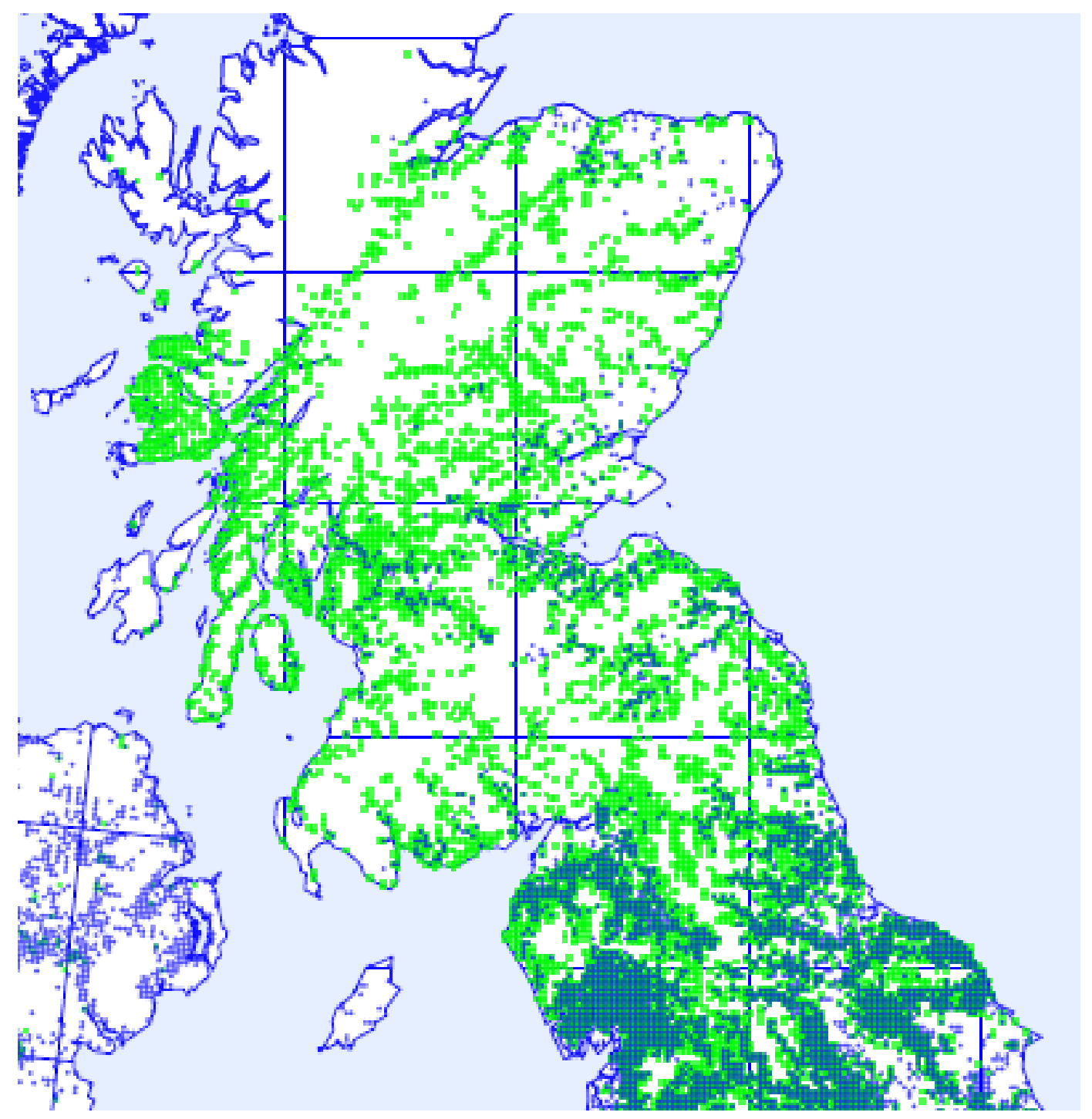

Figure 7. Arum maculatum (blue) over Mercurialis perennis (green)

Dipsacus fullonum (Fig. 8) may or may not be a British native. It was formerly cultivated for use in napping cloth (to give it a softer raised surface), often as a selected variety, and is now cultivated as a garden ornamental. It has become increasingly widely naturalised in the Scottish Borders on dry sunny slopes, often by rivers. It owes its presence in Scotland to man's activities, though it may be spread narrowly by the fruits adhering to animals. It is mapped here over Geranium pratense, a native grassland plant which has a broadly similar range. 


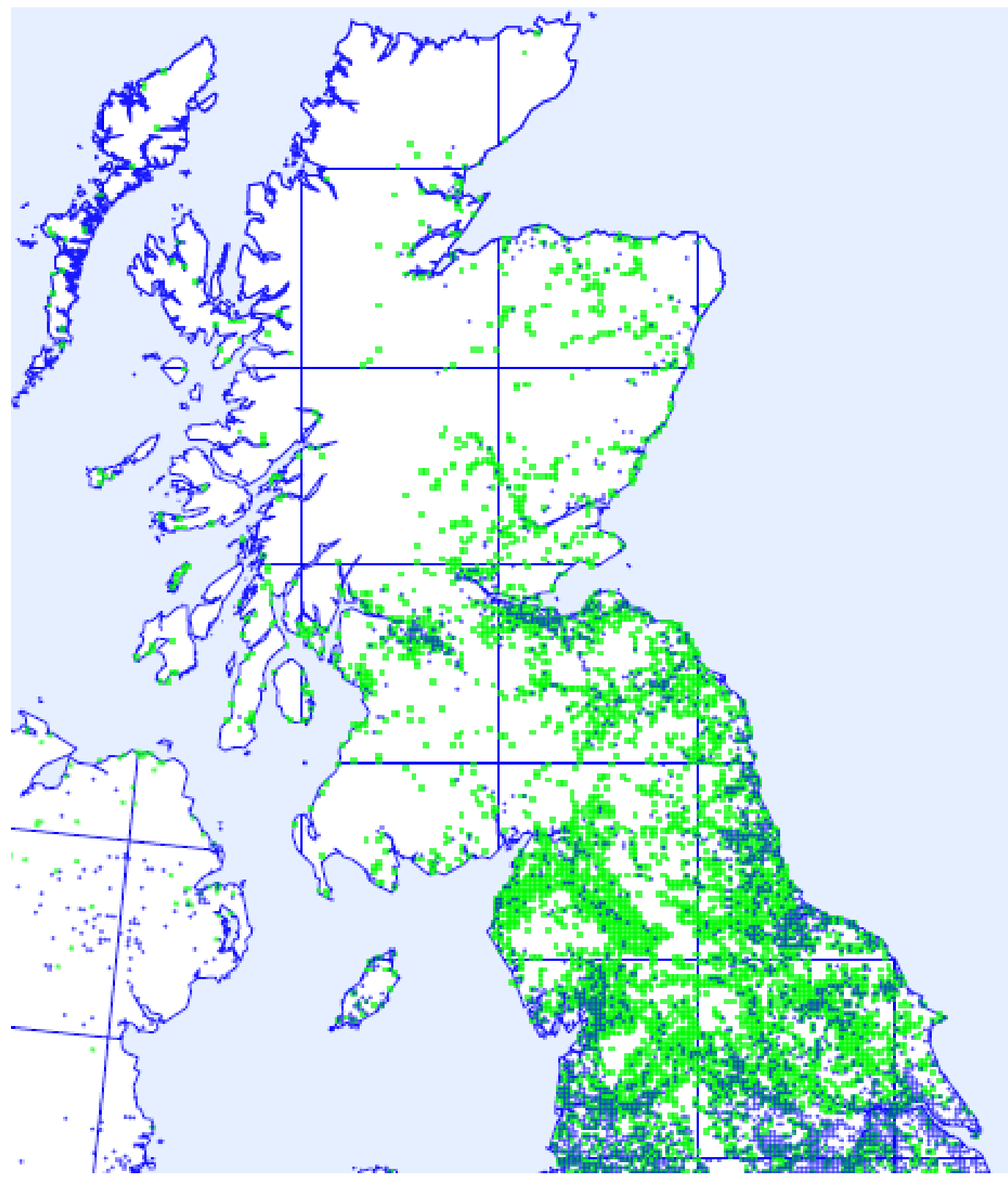

Figure 8. Dipsacus fullonum (blue) over Geranium pratense (green)

The map of Galium album over Cruciata laevipes (Fig. 9) is remarkable. While $C$. laevipes, a widespread species of neutral grassland, has a coherent distribution thinning out in Scotland, G. album is plentiful in northern England only in north Cumbria and the Tyne valley in Northumberland. There it colonises neutral grassland, in contrast to the more calcareous substrates favoured elsewhere in northern England. In Roxburghshire most of its sites are on the ballast of the disused Waverley Line railway to Edinburgh, a calcareous substrate. Surprisingly, it very rarely colonises adjacent neutral grassland. The situation elsewhere in Scotland is similar, with railways and industrial sites comprising most of the very scattered distribution. There are a few pre-railway sites in Berwickshire, but they are not grouped in a coherent way. Most have now died out and they may have been introductions with grass seed, hay, grain or straw. So G. album may well be an introduction in Scotland as a whole, with most sites relating to the construction of 
the railway network in the nineteenth century. In Cumbria, in contrast, the distribution suggests a distinct ecotype that has evolved locally at an unknown date. It is puzzling why this ecotype has not migrated north into Scotland.

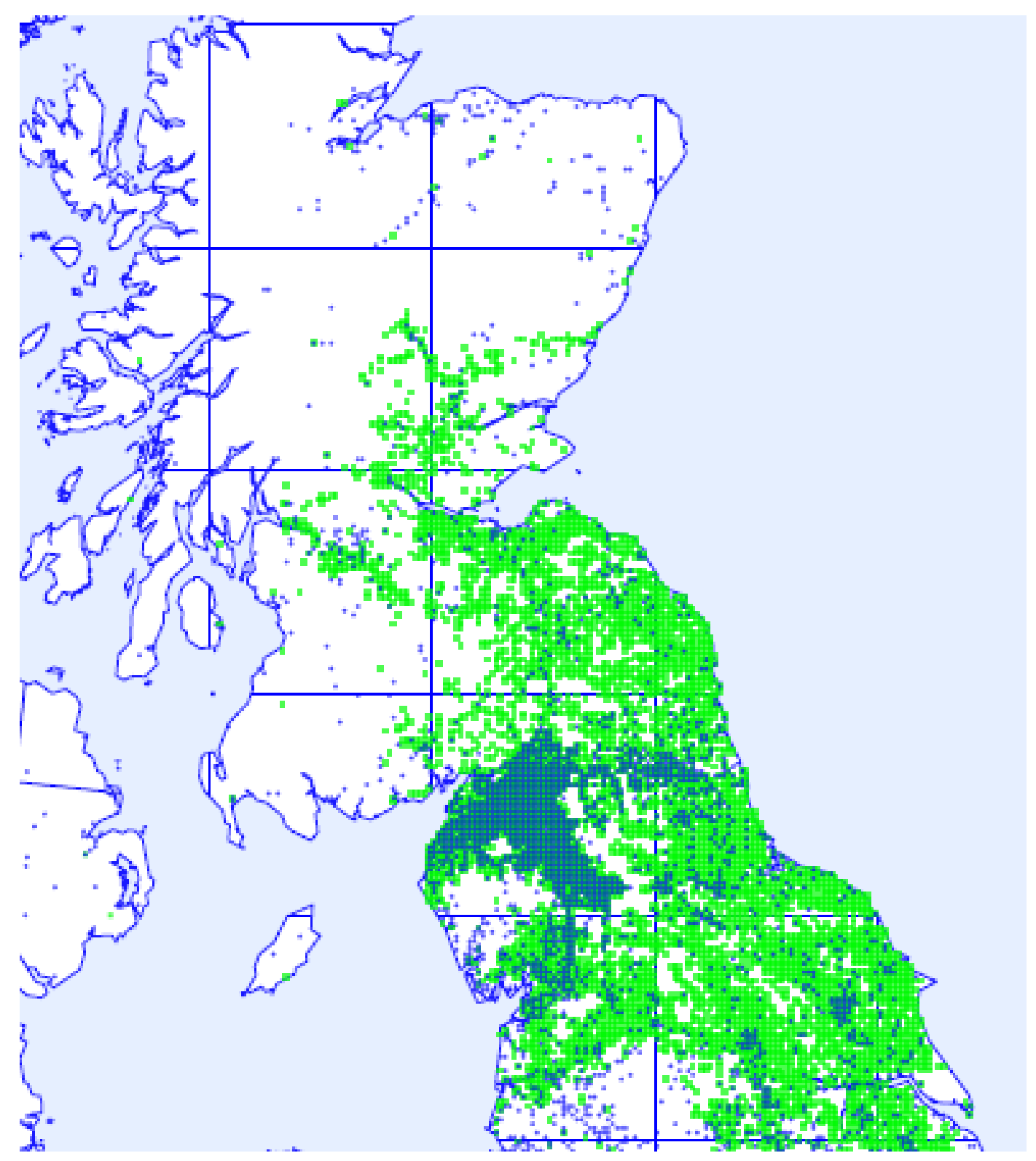

Figure 9. Galium album (blue) over Cruciata laevipes (green)

The Twentieth Century

Carex spicata (Fig. 10) is thinly but coherently distributed across northern England and has only a few scattered sites in Southern Scotland. The Scottish colonies are along road verges and railway bankings and appear to be introductions, though it may be fairer to consider them as natural migration along a newly-available habitat. While the sites are difficult to date, a cluster of sites along a recently realigned section of the A7 trunk road suggests that migration is recent and ongoing. Mapping C. spicata over $G$. pratense gives an indication of the habitats where further migration is possible. Climate change might be a factor favouring such northward migration. 


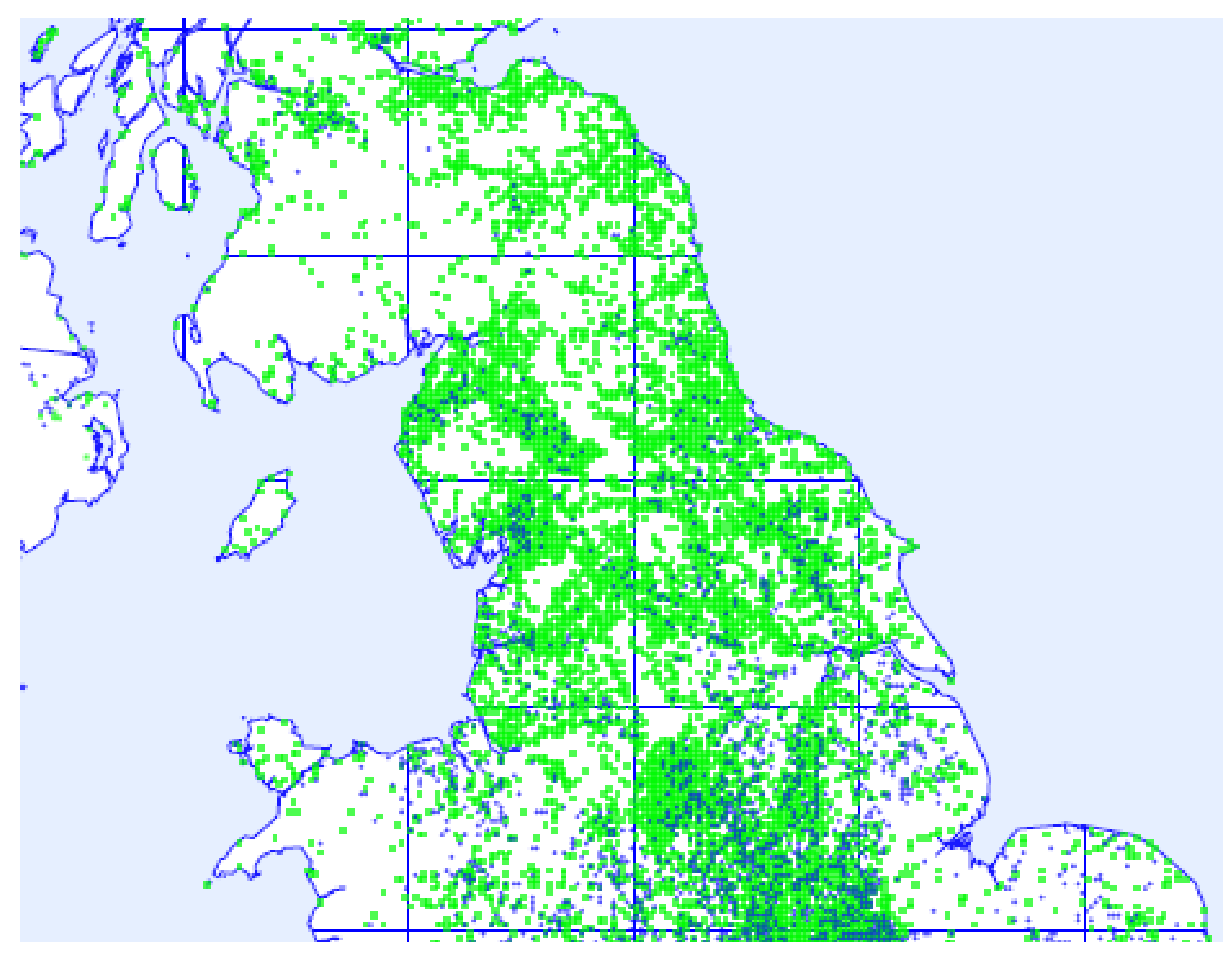

Figure 10. Carex spicata (blue) over Geranium pratense (green)

Lysimachia vulgaris (Fig. 11) was known in the Scottish Borders as a rare plant of tall-herb vegetation in fens long before it was discovered by the River Tweed. Two ecotypes may be involved. The first ecotype being a native that colonised fens at an early period from seed ingested by birds. The second ecotype was not recorded by the River Tweed until 1911, though it was reported by one of its tributaries, the Leader Water, in 1902 (Braithwaite, 2014). It is now plentiful by the Tweed and it is difficult to accept that it is not native there, until one learns that it only colonised the River Tyne in Northumberland over a similar period (Swan, 1993).

Its colonisation has followed the familiar route of a single point of colonisation being followed by vegetative dispersal of its robust rhizomes along rivers. It is mapped here over the native Scirpus sy/vaticus, another plant of river margins, which has been more successful at long-distance dispersal between river systems, probably with the assistance of seed ingested by birds. It is possible that the arrival of the second ecotype of L. vulgaris was also bird-assisted, but its history remains a mystery. 


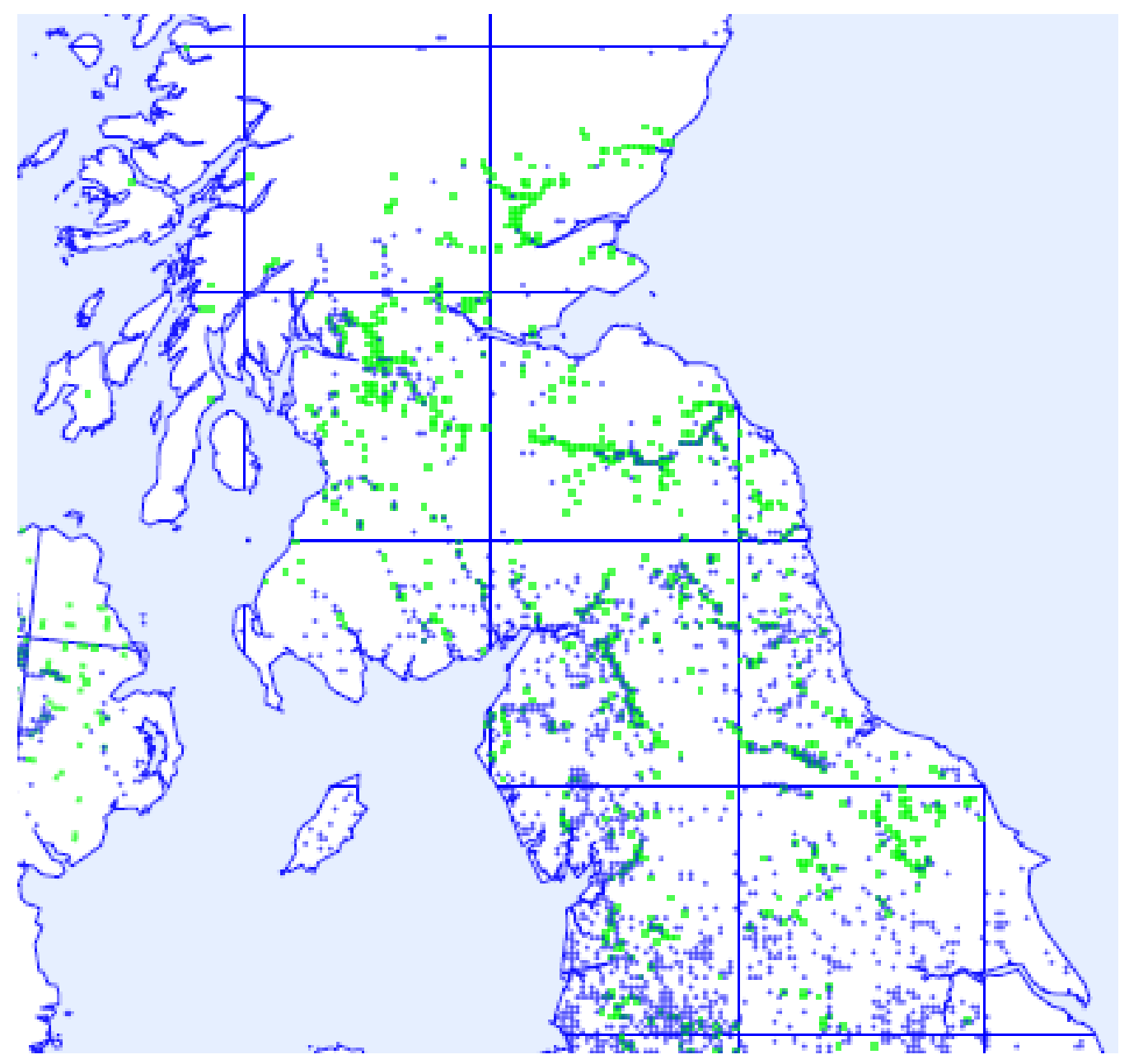

Figure 11. Lysimachia vulgaris (blue) over Scirpus sylvaticus (green)

Halophytes of road verges salted in winter

The most dramatic migration that I have observed has been the colonisation of road verges by a group of halophytes in the 1990's. The group includes Cochlearia danica, Puccinellia distans and Spergularia marina. While the species involved are native to Scotland, almost all the migration occurred as a wave spreading north from England along the major trunk roads, and then dispersing further locally. The phenomenon was reported fully in the New Atlas (Preston et al, 2002) and has been widely publicised since, so no further comment is offered, other than to wonder whether ecotypes adapted to the roadside habitat have evolved.

\section{The Twenty-first Century}

Erigeron acris and Poterium sanguisorba (Fig. 12) are two calcicole grassland species with correspondingly distinctive distributions. Poterium sanguisorba only just reaches Scotland, where it is in decline, while Erigeron acris was first recorded in Berwickshire only in 2019 in a small piece of ruderal habitat adjacent to the A1 trunk road. Erigeron acris has been known for a little longer elsewhere in Scotland, especially in the Lothians where, in the last two decades, it has begun to spread. Notably, it has formed thriving populations on the East Lothian coast, especially in the sandy grassland behind the dunes of the Aberlady Bay Local Nature Reserve, which parallel its native coastal sites in England. Erigeron acris, with its locally wind- 
dispersed seeds, has similarities with the alien Erigeron species that are colonising ruderal urban habitats. Erigeron acris appears to be colonising in the same way by utilising the transport network, with its seeds adhering to vehicles. What is exceptional is the way this species has found its way to native grassland, making a leap north that has eluded it over the centuries. Climate change may be a contributory factor.

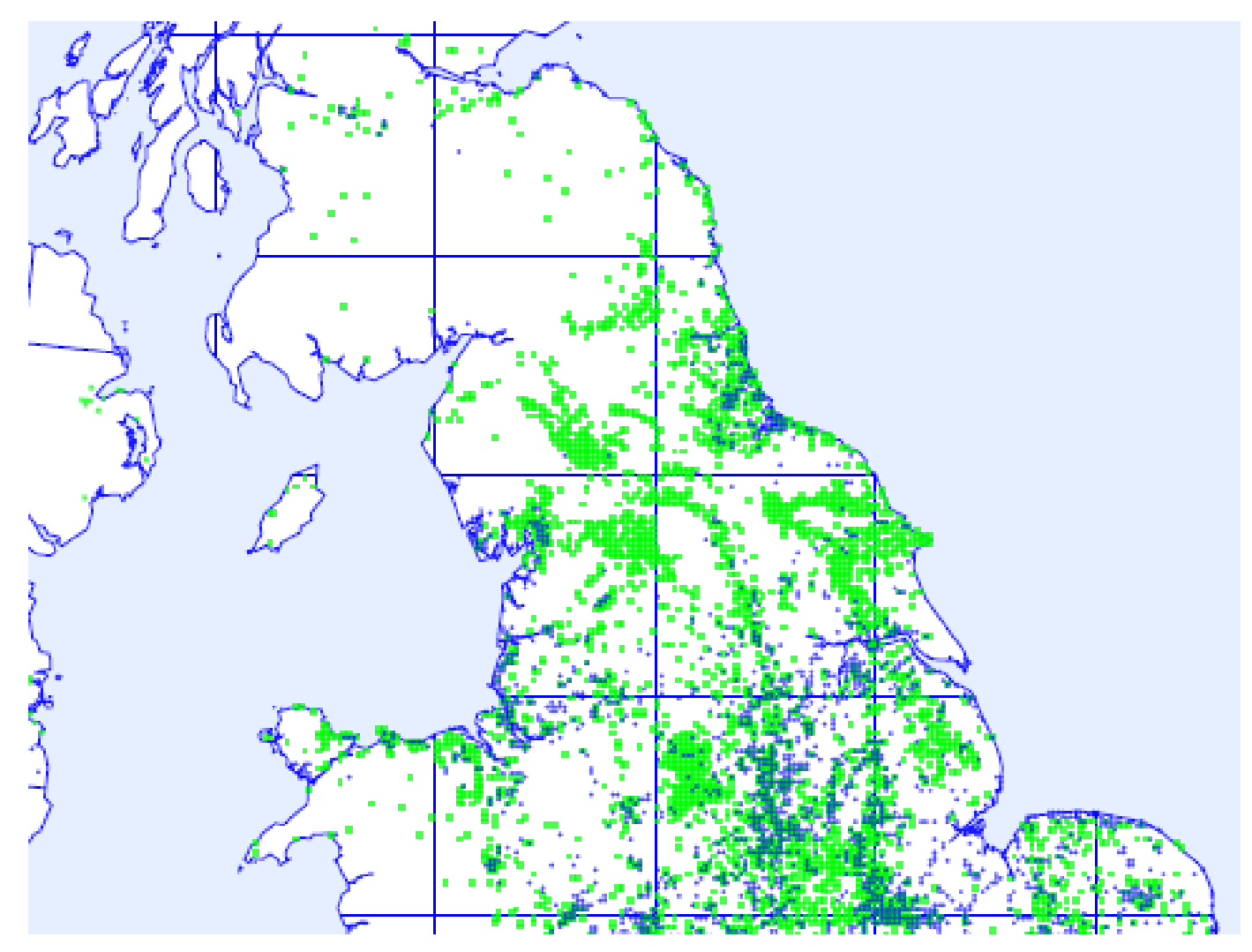

Figure 12. Erigeron acris (blue) over Poterium sanguisorba (green)

\section{Discussion}

It may seem presumptuous to try to allocate dates to the northward migration of plants within Britain on the basis of distribution maps, albeit with due regard to the literature of landscape change since the last Ice Age, but it is argued that the broad outline of this history does fall into place. The key is the decision to restrict the analysis to relatively scarce plants that lack specialised means of long-distance dispersal and whose migration would now be expected to be over, following the fragmentation of their natural habitats. For these, the coherence, or otherwise, of their tetrad distributions does give an indication of whether any part of their migrations has relied on the assistance of man's activities.

The example species discussed in detail do indeed point to a cessation of natural migration after the Neolithic period followed by numerous instances where man has wittingly or unwittingly brought about introductions. It is of particular interest to examine to what extent the introductions have naturalised in natural or semi-natural habitats, leading to 'genuine' increases in a species range, both for native species and archaeophytes. The following species have naturalised widely: Dipsacus fullonum in grassland, Arum maculatum and Myosotis sy/vatica in woodland 
and Myrrhis odorata along riversides. Carex spicata and Erigeron acris may be beginning to do so in grassland, but opportunities for naturalisation in today's landscape are few. The broad bankings adjoining railways and realigned sections of some major roads may offer the best opportunities available. Betonica officinalis and Galium album have naturalised only very narrowly in grassland. Spergularia rubra has continued to colonise, as it would appear to have been doing for centuries, but is almost exclusively restricted to artificial habitats and has hardly colonised the sandy coastline at all. The discussion of Lysimachia vulgaris, which has been spreading along riversides, suggests that two ecotypes are involved, a declining native ecotype of fens and a recently-arrived robust ecotype whose history is unclear, though it may have colonised the River Tweed from the River Tyne in Northumberland from seed ingested by birds and, if that is so, it does not strictly qualify for selection here, but is retained because of the issues that have come to light concerning its history.

\section{Conclusions}

The tetrad maps now available on BSBI's Distribution Database have provided many unexpected insights into the distributions of the selected species.

This study, albeit limited to a small sample of species, supports the expectation that plants that lack specialised means of long-distance dispersal have been prevented from migrating north across the Scottish Border by the fragmentation of the more specialised habitats, especially calcareous grassland. Evidence is presented that some such species have been able to migrate with the assistance of man's activities. There have been deliberate introductions followed by natural dispersal and much inadvertent introduction, often by seed adhering to vehicles or by seed being transported with construction materials.

Recent conservation sowings resulting in the colonisation of natural habitats have only been discussed in relation to Betonica officinalis, where the sample is insufficient to draw conclusions.

Climate change may be a driver in the ongoing migration of Carex spicata and Erigeron acris, while adverse climatic conditions may have been a factor in the failure of Betonica officinalis to naturalise widely in Scotland after its possible introduction in the Middle Ages.

\section{References}

Braithwaite, M.E. 2010. Presidential address: How well has BSBI chronicled the spread of neophytes? Watsonia 28: 21-31.

Braithwaite, M.E. 2014. A short Flora of Berwickshire. Hawick: privately published.

Braithwaite, M.E. 2016. Howes and knowes: an introduction to Berwickshire placenames. Berwick: The Berwickshire Naturalists' Club.

BSBI Distribution Database. [Accessed August 2020]. Available at $<$ https://database.bsbi.org/>.

Gilmour, J. \& Walters, M. 1969. The New Naturalist - Wild Flowers. 4th ed. London: Collins.

Grime, J.P., Hodgson, J.G. \& Hunt, R. 1990. The abridged Comparative Plant Ecology. London: Unwin Hyman.

Halliday, G. 1997. A Flora of Cumbria. Lancaster: Centre for North-West Regional Studies, University of Lancaster. 
Johnston, G. 1853. The Natural History of the Eastern Borders. London: J van Voorst.

Parry, M.L. \& Slater, T.R., eds. 1980. The making of the Scottish Countryside. London: Croom Helm.

Preston, C.D., Pearman, D.A. \& Dines, T.D., eds. 2002. New Atlas of the British and Irish Flora. Oxford: Oxford University Press.

Swan, G.A. 1993. Flora of Northumberland. Newcastle-upon-Tyne: The Natural History Society of Northumberland.

Copyright retained by author(s). Published by BSBI under the terms of the Creative Commons Attribution 4.0 International Public License.

ISSN: $2632-4970$

https://doi.org/10.33928/bib.2020.02.335 